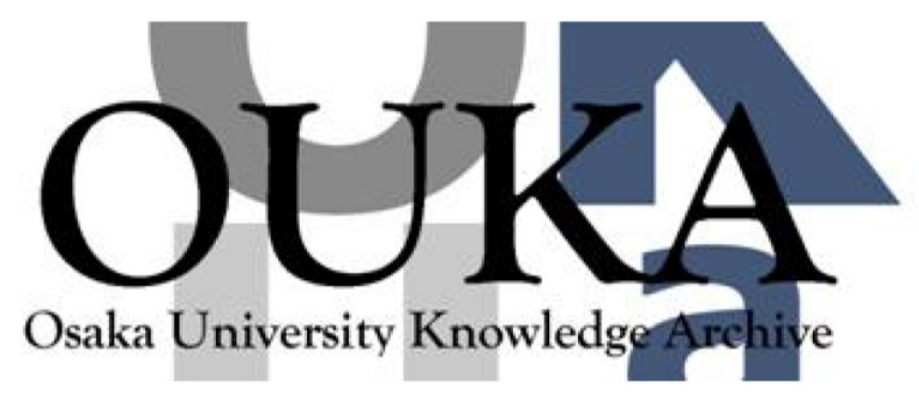

\begin{tabular}{|c|l|}
\hline Title & $\begin{array}{l}\text { Application of Bis(terpyridine) ruthenium(II) to } \\
\text { N-terminal amino acid sequencing }\end{array}$ \\
\hline Author(s) & $\begin{array}{l}\text { Okamura, Taka-aki; Iwamura, Taku; Ito, Akihiro } \\
\text { et al. }\end{array}$ \\
\hline Citation & CHEMISTRY LETTERS. 34(3) p.332-p. 333 \\
\hline Issue Date & $2005-03$ \\
\hline oaire:version & VoR \\
\hline URL & https://hdl. handle. net/11094/2892 \\
\hline rights & \\
\hline Note & \\
\hline
\end{tabular}

Osaka University Knowledge Archive : OUKA

https://ir. Library. osaka-u. ac. jp/

Osaka University 


\section{Application of Bis(terpyridine)ruthenium(II) to N-Terminal Amino Acid Sequencing}

Taka-aki Okamura, Taku Iwamura, Akihiro Ito, Maki Kaneko, Minoru Yamaguchi, ${ }^{\dagger}$ Hitoshi Yamamoto, Norikazu Ueyama, ${ }^{*}$

Hiroki Kuyama, ${ }^{\dagger}$ Eiji Ando, ${ }^{\dagger}$ Shigemi Norioka, ${ }^{\dagger \dagger}$ Takashi Nakazawa, ${ }^{\dagger \dagger}$ Ryoji Masui, ${ }^{\dagger \dagger \dagger}$ and Seiki Kuramitsu ${ }^{\dagger \dagger \dagger}$

Department of Macromolesular Science, Graduate School of Science, Osaka University, Toyonaka, Osaka 560-0043

${ }^{\dagger}$ Life Science Laboratory, Shimadzu Corporation, Kyoto 604-8511

${ }^{\dagger}$ Graduate School of FrontierBiosciences, Osaka University, Suita, Osaka 565-0871

†'Department of Chemistry, Nara Women's University, Nara 630-8506

${ }^{\dagger+\dagger}$ Department of Bioligy, Graduate School of Science, Osaka University, Toyonaka, Osaka 560-0043

(Received December 6, 2004; CL-041486)

A novel N-terminal-labeling reagent $\left[(\right.$ tpy $) \mathrm{Ru}^{\mathrm{II}}-$ $($ tpyCONSu $)]^{2+}(=<\mathrm{Ru}>-\mathrm{COONSu})$ provides an efficient and effective $\mathrm{N}$-terminal sequencing of peptides and proteins in MALDI-TOF-MS/MS (PSD) analysis, which shows $\mathrm{a}_{n}$ fragments predominantly without any $\mathrm{C}$-terminal-fragment ions.

Proteomics, which is defined as the exhaustive characterization of proteins, is believed to be the key to understanding cellular functions. Recent improvements in mass spectroscopy have enabled highly sensitive and rapid determination of amino acid sequences. ${ }^{1,2}$ Peptide mass finger printing ${ }^{3-7}$ and peptide sequence tag, ${ }^{8}$ which are based on the genome database, are effective methods used in protein sequencing. However, determining an accurate $\mathrm{N}$-terminal amino acid sequence is difficult even when employing these methods. Traditional and popular Edman degradation methods provide accurate $\mathrm{N}$-terminal sequences but require a large amount of samples for analysis.

Specific N-terminal modifications improve the sensitivity of the desired fragment ions in de novo sequencing. The active esters of 5-bromonicotinic acid ${ }^{9}$ or partially deuterated nicotinic acid $^{10}$ have been reported to show a characteristic isotope pattern, giving enhanced signals in mass analysis. The addition of sulfonic acid at the N-terminus reduces the intensity of N-terminal fragment ions and relatively enhances the intensity of C-terminal fragment ions. ${ }^{11,12}$ Although these reagents enhance the intensity of either $\mathrm{N}$ - or C-terminal fragment ions, strict distinction between $\mathrm{N}$ - and $\mathrm{C}$-terminal fragment ions and exclusion of undesired peaks are very difficult.

In our recent works on bis(terpyridine)ruthenium(II) derivatives, we have found the high sensitivity of the complexes in mass analysis ${ }^{13}$ and developed a novel N-terminal labeling reagent $\left[(\right.$ tpy $) \mathrm{Ru}^{\mathrm{II}}\left(\right.$ tpy- $\left.\left.\mathrm{C}_{6} \mathrm{H}_{4} \mathrm{COONSu}\right)\right] \mathrm{X}_{2} \quad$ (tpy $=$ terpyridine, $\mathrm{HONSu}=1$-hydroxysuccinimide, $\mathrm{X}=\mathrm{Cl}, \mathrm{PF}_{6}$ ), where the cationic part is abbreviated as $<\mathrm{Ru}>-\mathrm{COONSu}{ }^{14}$ This active ester is easily synthesized from the corresponding carboxylic acid, $<\mathrm{Ru}>-\mathrm{COOH}$. The $<\mathrm{Ru}>-\mathrm{CO}$ moiety has some favorable qualities, including the following: (a) is thermally and photochemically stable; (b) remains stable to acid, base, and enzymatic digestion; (c) undergoes ionization easily because of its cationic part; (d) has a characteristic isotope pattern based on stable isotopes, ${ }^{96} \mathrm{Ru},{ }^{98} \mathrm{Ru}-{ }^{102} \mathrm{Ru}$, and ${ }^{104} \mathrm{Ru}$; and (e) has a high enough molecular weight $(<\mathrm{Ru}>-\mathrm{CO}$ : M.W. = ca. 671$)$ to exclude unwelcome small fragment ions. This reagent is tough enough to carry out coupling with proteins and digestion followed by MALDI-TOF-MS analysis without undergoing any decomposition and is capable of being detected by mass spectroscopy. (a)

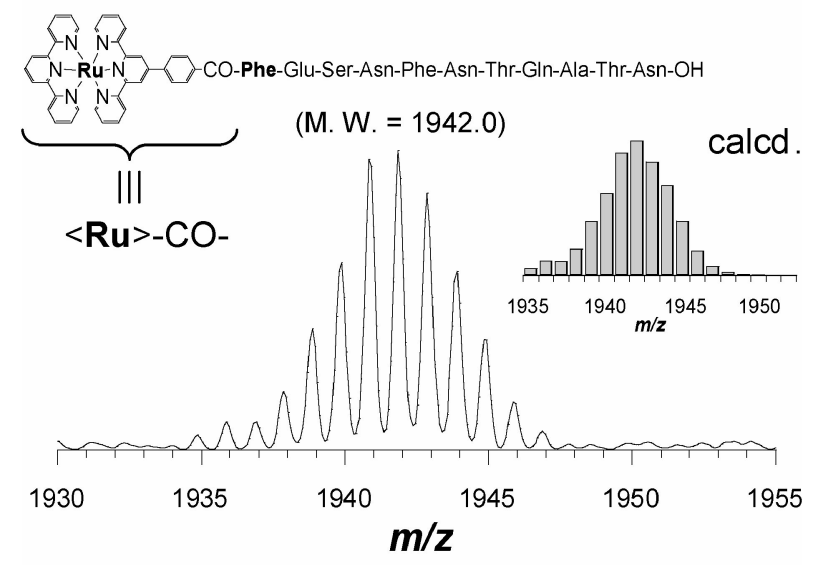

(b)

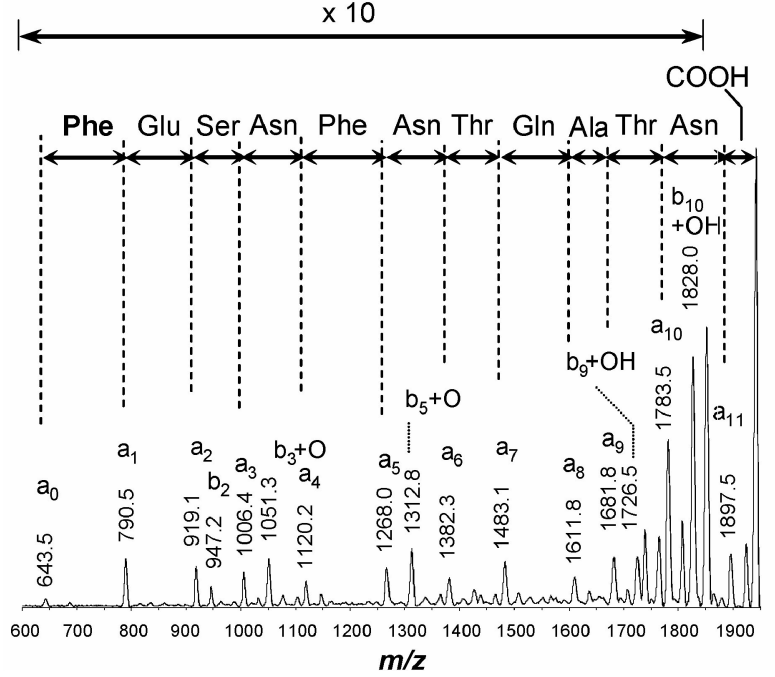

Figure 1. (a) MALDI-TOF-MS and (b) PSD (MS/MS) spectra of $<$ Ru $>$-CO-Phe-Glu-Ser-Asn-Phe-Asn-Thr-Gln-Ala-Thr-Asn$\mathrm{OH}$.

This reagent readily reacts with an amino group in peptides to produce $<\mathrm{Ru}>-\mathrm{CO}$ labeled peptides. A series of peptides based on chicken lysozyme fragments, Phe-Glu-Ser-Asn-PheAsn-Thr-Gln-Ala-X ( $\mathrm{X}=$ none, Thr, Thr-Asn, or Thr-Asn$A r g$ ), were synthesized and coupled with this reagent to examine the dependence on the length and type of C-terminal residue. A typical MALDI-TOF-MS spectrum (Shimadzu/Kratos AXIMA$\mathrm{CFR}$ ) of the isolated $<\mathrm{Ru}>$-CO-labeled peptide is shown in 


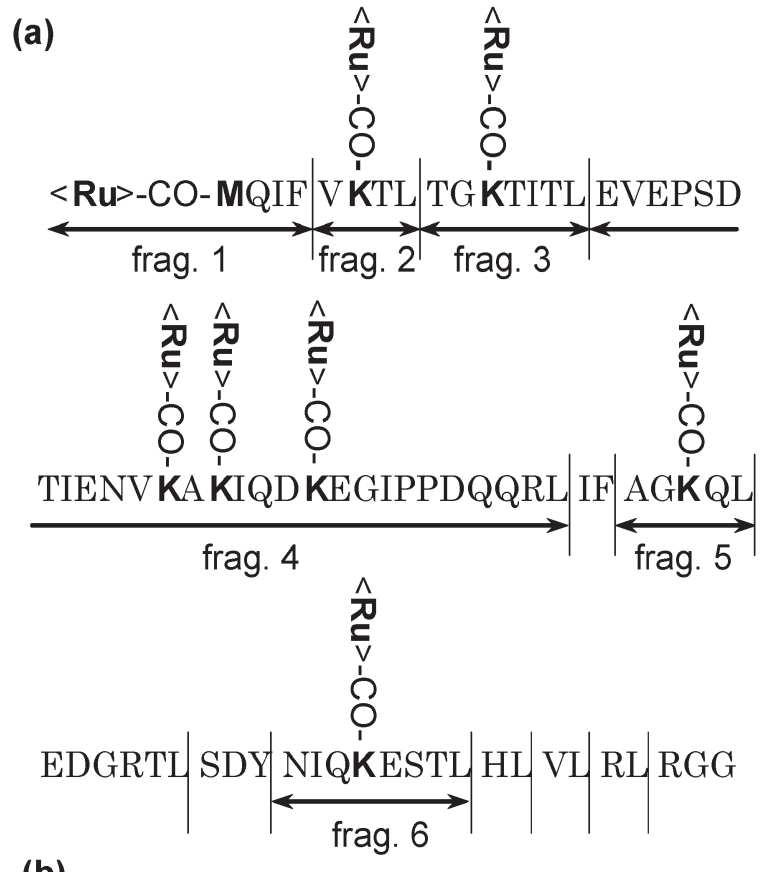

(b)

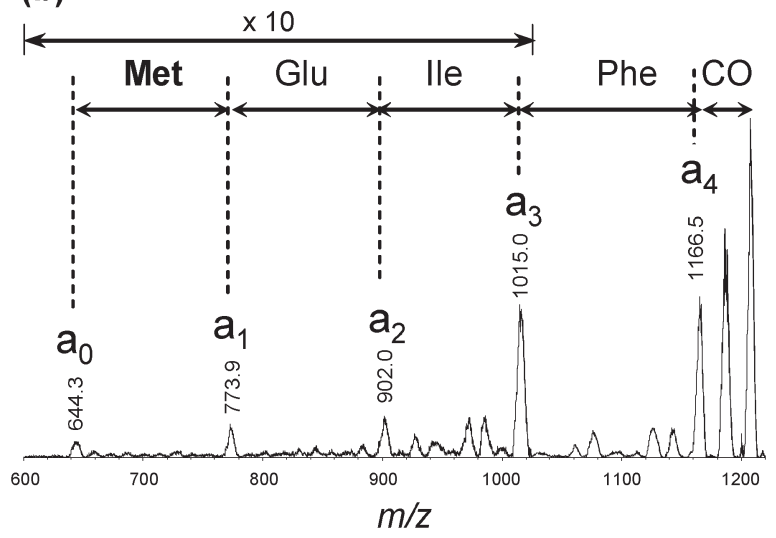

Figure 2. (a) Sequences of $<\mathrm{Ru}>-\mathrm{CO}$-labeled ubiquitin and chymotryptic fragments. The vertical lines indicate chymotoriptic digested points. (b) PSD spectrum of the fragment 1.

Figure 1a. The characteristic isotope pattern is in perfect accordance with the simulated spectrum assuming half of the ruthenium ions were reduced to $\mathrm{Ru}^{\mathrm{I}}$. A PSD (post source decay, MS/ MS) spectrum of the peak at $m / z=1942$ is shown in Figure 1 b. Desired peaks were distinguished easily from the other peaks by their characteristic pattern. A complete series of $a_{n}$ fragment ions, which are $\mathrm{N}$-terminal fragments cleaved at $\mathrm{C}_{\alpha}$-carbonyl bonds, were observed. Minor peaks are $b_{n}$ fragment ions formed by the cleavage at carbonyl-N bonds. No C-terminal fragment ions were observed. From $\mathrm{a}_{0}(=<\mathrm{Ru}>-)$, the amino sequences can be read successively to reach the $\mathrm{C}$-terminus. Similar spectra were obtained for the other peptides. This method provides highly sensitive, specific, and ready detection of $\mathrm{N}$-terminal fragment ions, especially the $\mathrm{a}_{n}$ series, without detecting $\mathrm{C}$-terminal fragment ions and other contaminated ions, thus making $\mathrm{N}$-terminal amino acid sequencing both efficient and rapid.

In the case of proteins, bovine ubiquitin was used to establish a general procedure for $\mathrm{N}$-terminal sequencing. This protein consists of 76 amino acid residues, including 7 lysine $(\mathrm{K})$ resi- dues as shown in Figure 2a. When $<\mathrm{Ru}>-\mathrm{COONSu}$ reacts to bovine ubiquitin, the $<\mathrm{Ru}>-\mathrm{CO}$ groups are introduced up to 8 points ( $\mathrm{N}$-terminal and 7 Lys $\varepsilon$-amino groups). Based on the MALDI-TOF-MS spectra of the whole $<$ Ru $>-C O-l a b e l e d ~ u b i q-$ uitin, the number of the labeling is 3-8. After chymotriptic digestion, $<\mathrm{Ru}>-\mathrm{CO}$-labeled peptides were observed in MALDI-TOF-MS spectra without unlabeled fragment ions.

The PSD-MALDI-TOF-MS spectrum of fragment $1(\mathrm{~m} / \mathrm{z}=$ 1208 ) is shown in Figure 2b. Only a series of $a_{n}$ fragment ions were found. The spectrum clearly shows the N-terminal sequences, MQIF.

In summary, we have demonstrated efficient $\mathrm{N}$-terminal amino acid sequencing through the use of a novel bis(terpyridine)ruthenium(II) labeling method. This conceptually new application of a stable cationic transition metal complex to mass analysis resulted in a highly sensitive and accurate determination of N-terminal amino acid sequences. The detection limit is $\leq 10 \mathrm{fmol}$ which is enough to analyze each spot in 2-DE (2 dimensional electrophoresis) separation, where the detection by staining of gel requires ca. $100 \mathrm{f} \mathrm{mol} .{ }^{15}$ To contribute further to the study of proteomics, we are now applying this method to unknown proteins of thermophilic bacteria, which will be reported elsewhere.

The authors gratefully thank Dr. Susumu Tsunasawa for his insightful suggestions and comments. This work was supported in part by the National Project on Protein Structural and Function Analyses, Japan; and a Grant-in-Aid from the Ministry of Education, Culture, Sports, Science and Technology, Japan. One of the authors (A. I.) expresses his special thanks for the center of excellence (21COE) program "Creation of Integrated EcoChemistry of Osaka University".

\section{References}

1 R. Aebersold and M. Mann, Nature, 422, 198 (2003).

2 R. Aebersold and D. R. Goodlett, Chem. Rev., 101, 269 (2001).

3 P. James, M. Quadroni, E. Carafoli, and G. Gonnet, Biochem. Biophys. Res. Commun., 195, 58 (1993).

4 J. R. III. Yates, S. Speicher, P. R. Griffin, and T. Hunkapiller, Anal. Biochem., 214, 397 (1993).

5 D. J. C. Pappin, P. Hojrup, and A. J. Bleasby, Curr. Biol., 3, 327 (1993).

6 M. Mann, P. Hojrup, and P. Roepstorff, Biol. Mass Spectrom., 22, 338 (1993).

7 W. J. Henzel, T. M. Billeci, J. T. Stults, S. C. Wong, C. Grimley, and C. Watanabe, Proc. Natl. Acad. Sci. U.S.A., 90, 5011 (1993).

8 M. Mann and M. Wilm, Anal. Chem., 66, 4390 (1994).

9 M. Miyagi, M. Nakao, T. Nakazawa, I. Kato, and S. Tsunasawa, Rapid Commun. Mass Spectrom., 12, 603 (1998).

10 M. Münchbach, M. Quadroni, G. Miotto, and P. James, Anal. Chem., 72, 4047 (2000).

11 T. Keough, R. S. Youngquist, and M. P. Lacey, Proc. Natl. Acad. Sci. U.S.A., 96, 7131 (1999).

12 D. Wang, S. R. Kalb, and R. J. Cotter, Rapid Commun. Mass Spectrom., 18, 96 (2004).

13 T. Okamura, T. Iwamura, S. Seno, H. Yamamoto, and N. Ueyama, J. Am. Chem. Soc., 126, 15972 (2004); M. Kaneko, R. Masui, K. Ake, Y. Kousumi, S. Kuramitsu, M. Yamaguchi, H. Kuyama, E. Ando, S. Norioka, T. Nakazawa, T. Okamura, H. Yamamoto, and N. Ueyama, J. Proteome Res., 3, 983 (2004).

14 N. Ueyama, T. Okamura, S. Norioka, T. Nakazawa, H. Kuyama, and E. Ando, U. S. Patent 20040029181 (2004).

15 H. Katayama, K. Satoh, M. Takeuchi, M. Deguchi-Tawarada, Y. Oda, and T. Nagasu, Rapid Commun. Mass Spectrom., 17, 1071 (2003). 